\title{
Abrupt climate changes for Iceland during the last millennium: Evidence from high resolution sea ice reconstructions
}

\author{
Guillaume Massé ${ }^{\mathrm{a}, *}$, Steven J. Rowland ${ }^{\mathrm{a}}$, Marie-Alexandrine Sicre ${ }^{\mathrm{b}}$, Jeremy Jacob ${ }^{\mathrm{c}}$, \\ Eystein Jansen ${ }^{\mathrm{d}}$, Simon T. Belt ${ }^{\mathrm{a}}$ \\ a Petroleum and Environmental Geochemistry Group, Centre for Chemical Sciences, School of Earth, Ocean and Environmental Sciences, \\ University of Plymouth, Drake Circus, Plymouth, Devon, PL4 8AA, UK \\ ${ }^{\mathrm{b}}$ Laboratoire des Sciences du Climat et de l'Environnement, Domaine du CNRS, Avenue de la Terrasse, Bat.12, 91198 Gif-sur-Yvette Cedex, France \\ c Institut des Sciences de la Terre d'Orléans, UMR 6113, 45000 Orléans, France \\ d Bjerknes Centre for Climate Research, Allegaten 55, Bergen 5007, Norway
}

\section{A R T I C L E I N F O}

\section{Article history:}

Received 6 December 2007

Received in revised form 8 February 2008

Accepted 3 March 2008

Available online 18 March 2008

Editor: H. Elderfield

\section{Keywords:}

highly branched isoprenoid alkenes

sea ice

Iceland

sediments

\begin{abstract}
A B S T R A C T
A high resolution account of Icelandic sea ice over the last millennium has been constructed using a novel proxy based on the presence in sediments of a biomarker $\left(\mathrm{IP}_{25}\right)$ produced by sea ice algae. Comparison with historical sea ice records demonstrates a strong correlation between documented sea ice occurrences and the $\mathrm{IP}_{25}$ proxy. An excellent agreement is also observed between the $\mathrm{IP}_{25}$ record and a diatom-based sea surface temperature reconstruction obtained from the same core and the Crowley and Lowery Northern Hemisphere temperature reconstruction. Using this approach, we provide new historical sea ice data for periods where records are scarce or absent and evidence for abrupt changes to sea ice and/or climate conditions around Iceland during the Little Ice Age.
\end{abstract}

(c) 2008 Elsevier B.V. All rights reserved.

\section{Introduction}

Given the current debate regarding climate change on Earth and, in particular, the relative contributions of natural processes and anthropogenic inputs, it is crucial to obtain a clear and detailed account of past climatic variations and the factors controlling these (Jones et al., 2001). Polar sea ice, by its influence on the heat exchanges between the oceans and the atmosphere and its contributions to numerous oceanic processes (e.g. thermo-haline circulation) is a key component of the Earth's climate system (Thomas and Dieckmann, 2003). Therefore, improving our knowledge of historical sea ice fluctuations at a high spatial and temporal resolution will help to refine future climate change models and improve predictions. Very few documentary records for sea ice exist which pre-date the instrument era and these often include unreliable data (Bergthórsson, 1969; Ogilvie and Jónsson, 2001). Here, we report a detailed analysis of a sediment core (MD99-2275) collected from the North Icelandic Shelf (Fig. 1). This area is under the strong influence of three surface currents (Fig. 1). The warm and high salinity Irminger current is a branch of the North Atlantic drift, travelling along the western and the north western coasts of Iceland, while the East Greenland and the East Icelandic

\footnotetext{
* Corresponding author. Tel.: +44 1752233 032; fax: +44 1752232089. E-mail address: gmasse@plymouth.ac.uk (G. Massé).
}

currents bring cold and low salinity polar waters to the region. Any change in the relative strengths of these currents will influence the position of the oceanic Polar Front, and this is likely to be archived in the sediment record (Knudsen et al., 2004).

In this study, we have used the recently established sea ice proxy, $\mathrm{IP}_{25}$ (Belt et al., 2007), which is based on the preservation in marine sediments of a unique chemical fossil produced by sea ice algae (Fig. 2), to obtain an uninterrupted, high resolution (ca. 2-5 yr) record of sea ice occurrences for the last millennium. The very high sedimentation rates associated with the core location, together with well documented occurrences of volcanic tephras (Eiriksson et al., 2004; Knudsen and Eiriksson, 2002; Larsen et al., 2002; Rousse et al., 2006) have enabled us to perform this study at an unprecedented sub-decadal resolution and to make comparisons with historical data documenting past sea ice extending back to the early days of Icelandic colonization (ca. 1080 BP). We demonstrate strong correlations between documented sea ice occurrences and the $\mathrm{IP}_{25}$ proxy (Bergthórsson, 1969; Ogilvie and Jónsson, 2001) and reveal new sea ice data for periods where historical sources are scarce or absent. We have also compared our $\mathrm{IP}_{25}$ data with diatom-based sea surface temperature reconstructions (Jiang et al., 2005; Eiriksson et al., 2006) to confirm that the Icelandic climate was relatively mild, and that little sea ice occurred in the region from 800 to 1300 AD, corresponding to the end of the Warm Mediaeval Period (MWP). In contrast, both reconstructed sea ice and sea surface 


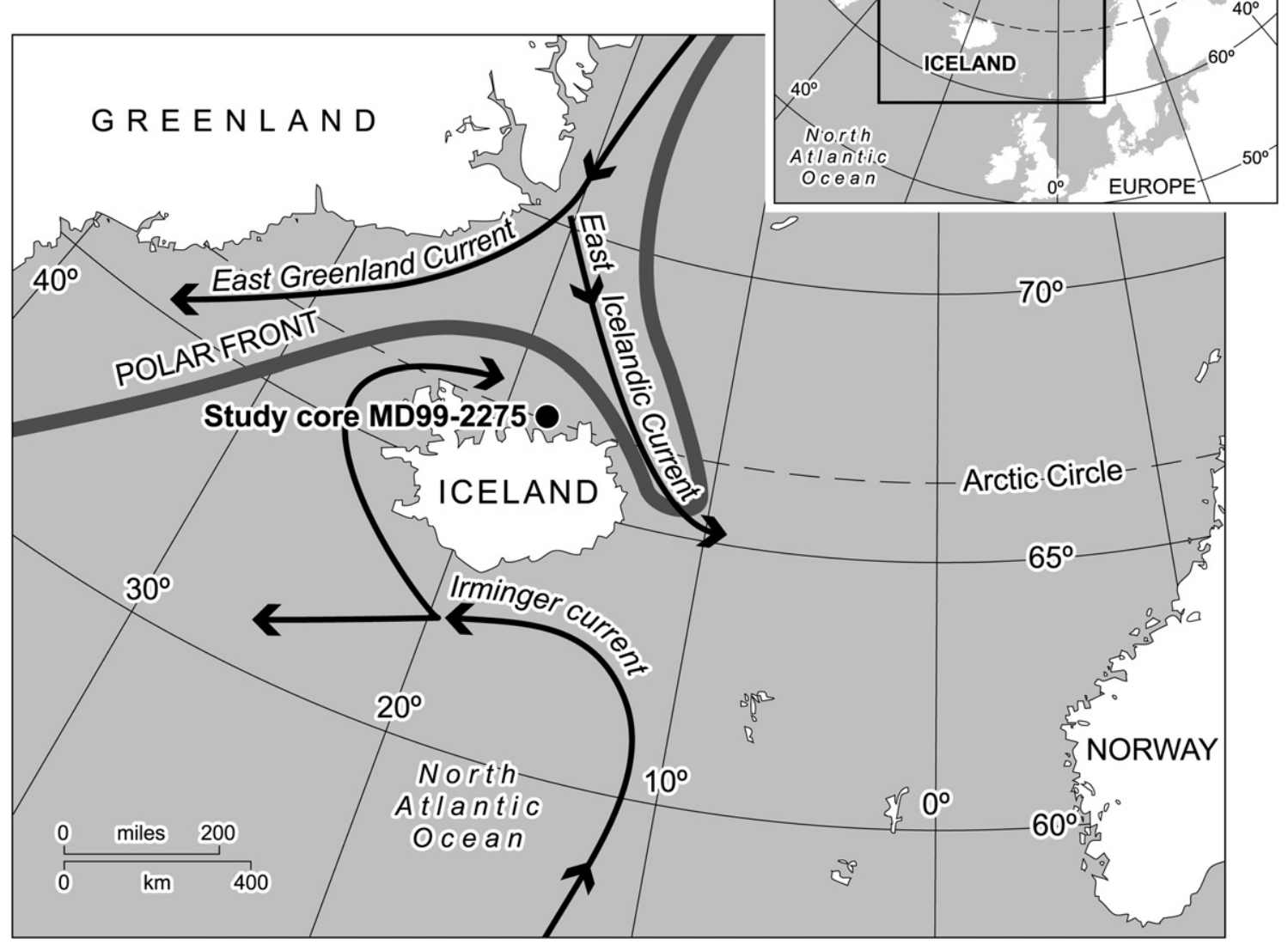

Fig. 1. Core location and oceanographic settings.

temperatures show that the climatic conditions around northern Iceland worsened during the second part of the millennium with cooler sea surface temperatures and larger amounts of sea ice. More detailed correlations exist throughout the record, and also provide evidence for a succession of abrupt climate changes in Iceland during the latter part of the record, corresponding to the Little Ice Age (LIA, 1300-1900 AD). Finally, our sea ice record also shows strong correlations with hemispheric-scale temperature reconstructions (Crowley, 2000; Mann et al., 1998), indicating that climatic conditions over Iceland were representative for at least the last millennium. This case study demonstrates that $\mathrm{IP}_{25}$ is a reliable proxy for historical sea ice reconstructions and could become an invaluable tool for high or ultra-high resolution studies of the Earth's climate system.

\section{Methods}

\subsection{Sediment samples}

The core MD99-2275 (66 33.06'N, 17 41, 59'W; 410 m water depth) was collected during the R/V Marion Dufresne IMAGES V cruise in 1999. The age model of the entire core was determined using a combination of tephra marker horizons and thirty five radiocarbon dates (Eiriksson et al., 2004; Knudsen and Eiriksson, 2002; Larsen et al., 2002; Rousse et al., 2006). This age model was further constrained using 6 tephra layers corresponding to the time period examined in the present study according to the method of Sicre et al. (2008).

\section{2. $I P_{25}$ analysis}

The core was sampled continuously at $1 \mathrm{~cm}$ intervals (2-5 yr). Freeze-dried sediments were extracted using dichloromethane/methanol (50/50) to yield a total organic extract. Hydrocarbon fractions were obtained from this extract using open column chromatography $\left(\mathrm{SiO}_{2}\right.$, hexane). An internal standard was added (7-hexylnonadecane, $0.1 \mu \mathrm{g}$ sample ${ }^{-1}$ ) to permit quantification by GC-MS. $\mathrm{IP}_{25}$ was identified on the basis of comparisons between its GC retention index and mass spectrum

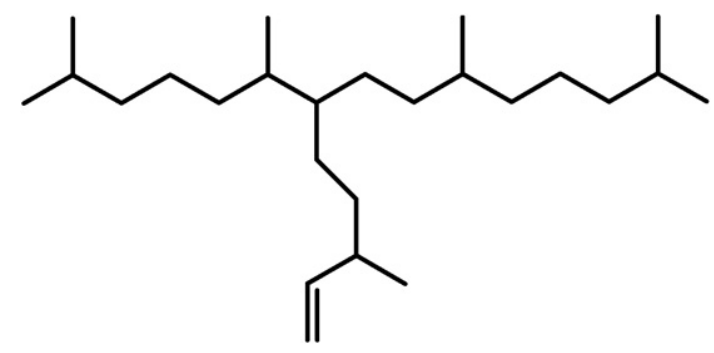

Fig. 2. Structure of $\mathrm{IP}_{25}$ proxy biomarker. 


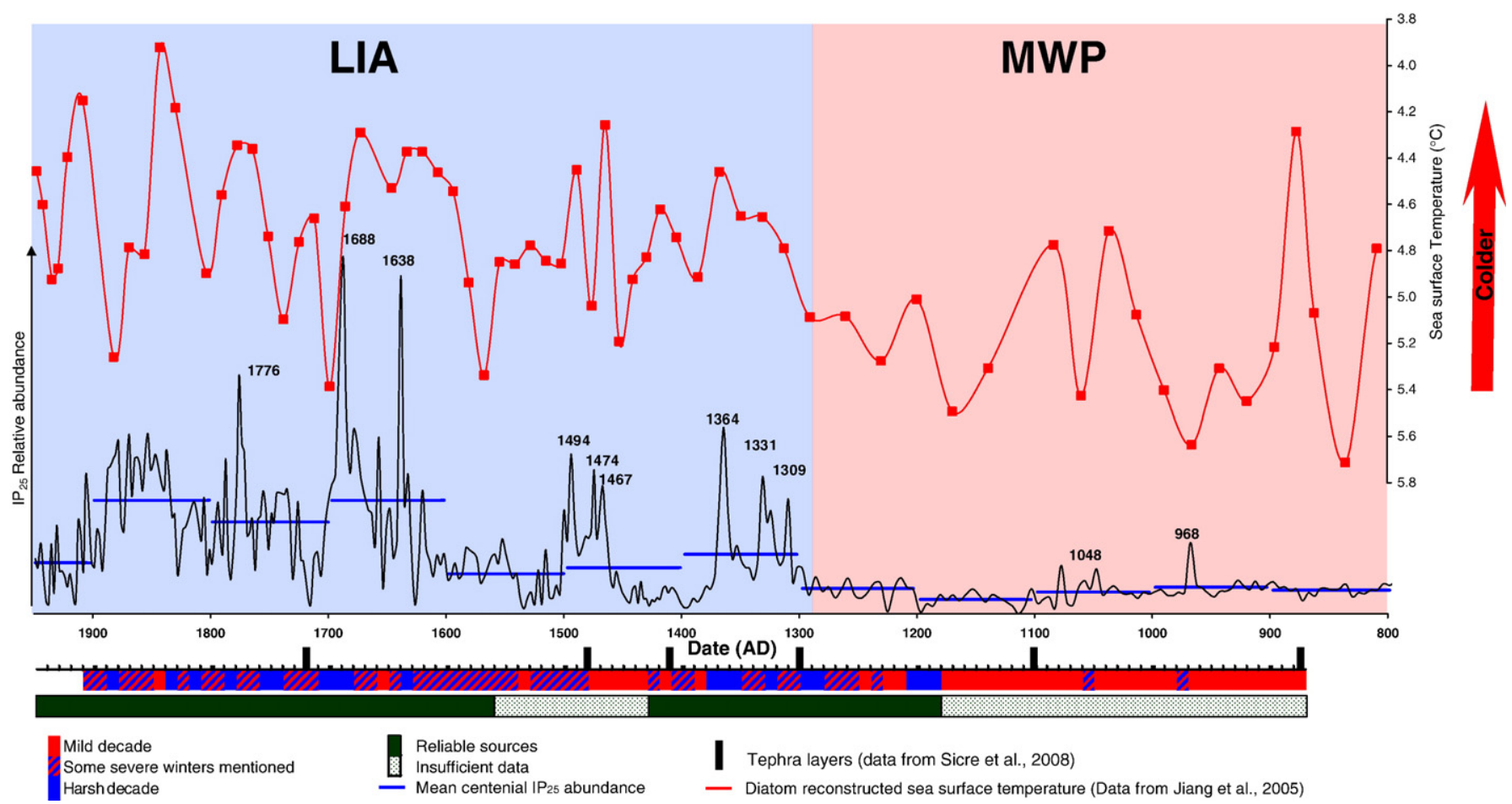

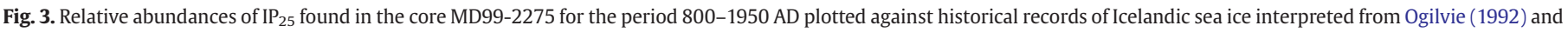
Ogilvie and Jónsson (2001) (bottom scales) and diatom-based reconstructed sea surface temperature (Jiang et al., 2005).

with an authentic standard (Belt et al., 2007). Relative abundances of $\mathrm{IP}_{25}$ were calculated on the basis of the individual GC-MS responses for $\mathrm{IP}_{25}$ and the internal standard, together with the mass of sediment analysed for each $1 \mathrm{~cm}$ interval.

\subsection{Previous studies}

\subsubsection{Sea ice studies}

There are a number of historical sources that document past sea ice occurrence around Iceland back to the early days of colonisation. These sources have been carefully analysed and interpreted enabling qualitative sea ice indices (as indicated by the symbols and descriptors in Fig. 3) to be developed (Koch, 1945; Bergthórsson, 1969). Most recently, Ogilvie (1992) and Ogilvie and Jónsson (2001) examined the reliability of some of the original sources to further refine these indices.

\subsubsection{Diatom-based sea surface temperature reconstructions}

Recently, Jiang et al. (2005) and Eiriksson et al. (2006) reconstructed past sea surface temperatures around the North Icelandic Shelf using the relative abundances of diatom frustules in sediments

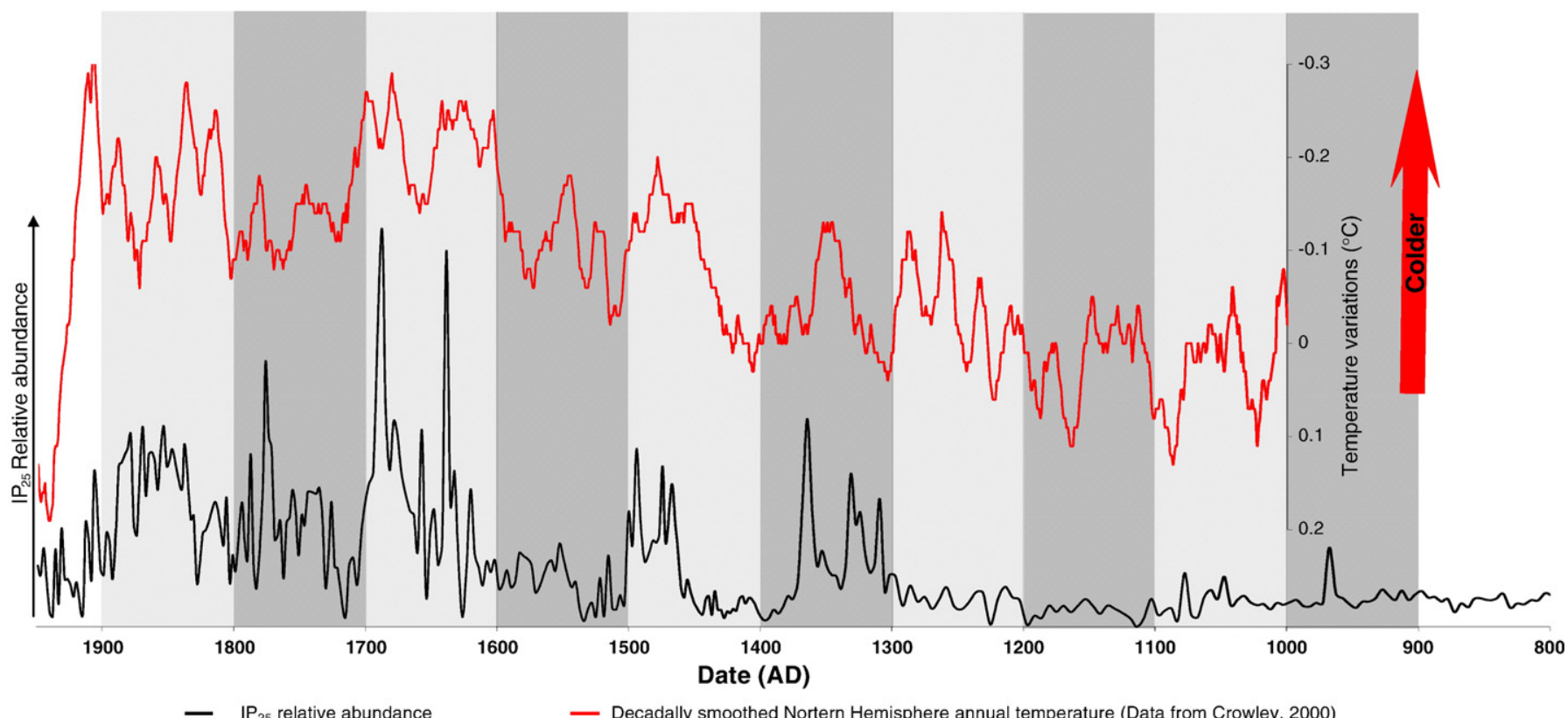

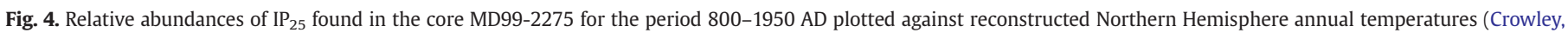
2000). 
from the core MD99-2275. In the current study, we have used the Jiang et al. (2005) dataset which is available at: ftp://rock.geosociety. org/pub/reposit/2005/2005010.pdf.

\subsection{Study site}

For the current study, we chose a site location close to the north coast of Iceland since this region is strongly influenced by the boundaries of the cold and low-salinity waters of the East Icelandic Current and the warmer and higher salinity waters associated with the Irminger Current (Eiriksson et al., 2004; Knudsen and Eiriksson, 2002; Larsen et al., 2002; Rousse et al., 2006). As such, analysis of a sediment core from this region should provide an excellent case study for interrogating substantial and rapid changes to sea ice cover which, in turn, may reveal relationships to more global climatic forcing (e.g. the North Atlantic Oscillation) on relatively short timescales, for which there is little previous evidence.

\section{Results and discussion}

Palaeoclimate scientists continue to emphasise the importance of data derived from so-called proxy methods for climate reconstruction and that such data should have both high temporal and spatial resolution if it is to be valuable for both historical determinations and future climate prediction models (Mann et al., 1998; Jones et al., 1998, 2001). Such studies routinely rely on a multi-proxy approach since direct measures of climate conditions are either scarce, absent or unreliable. For example, a paucity of historical sea ice records has sometimes been interpreted as an indication of ice free conditions (Ogilvie and Jónsson, 2001) which is potentially misleading since poor records can also be attributed to abrupt changes to population resulting from famine and epidemics. In addition, proxy data usually reflects mean annual or multiannual temperatures rather than seasonally sensitive phenomena such as sea ice. Recently, we reported a new proxy for Arctic sea ice, $\mathrm{IP}_{25}$, which is a mono-unsaturated highly branched isoprenoid (HBI) alkene biosynthesised by sea-ice diatoms (Belt et al., 2007; Fig. 2). HBI alkenes are commonly occurring chemicals found in a wide range of marine sediments (Rowland and Robson, 1990). However, Rowland and coworkers (2001) showed that the extent of HBI unsaturation reflected the growth temperature of the diatoms responsible for their production, with more saturated isomers being formed at low temperatures. Consistent with these observations, $\mathrm{IP}_{25}$ is a mono-unsaturated $\mathrm{HBI}$ alkene only found in sea ice and related sediments and is therefore considered as a specific biomarker of sea ice (Belt et al., 2007).

Fig. 3 shows a continuous record of the relative abundance of $\mathrm{IP}_{25}$ for the top (ca. $300 \mathrm{~cm}$ ) of the MD99-2275 sediment core. These results, when compared with climatic data from previous studies (Ogilvie, 1992; Crowley and Lowery, 2000; Jones et al., 2001; Ogilvie and Jónsson, 2001; Knudsen et al., 2004; Eiriksson et al., 2006; Jiang et al., 2005) show a series of excellent correlations (Figs. 3 and 4). Firstly, averaged centennial-scale abundances of $\mathrm{IP}_{25}$ are entirely consistent with previous estimations of the Little Ice Age (LIA), the Mediaeval Warm Period (MWP) and relative centennial temperatures (Jones et al., 2001; Ogilvie and Jónsson, 2001). For example, centennial-scale $\mathrm{IP}_{25}$ abundances are highest for the 19th and 17th centuries (Fig. 3) in-line with the conclusions of Crowley (2000), Jones et al. $(1998,2001)$ and Mann et al. (1998) that these were the coldest centuries of the last millennium in the northern hemisphere. In contrast, $\mathrm{IP}_{25}$ abundances are substantially reduced during the 18th and 16th centuries as well as for the first half of the millennium (Fig. 3) due to lower sea ice occurrences associated with warmer conditions (Jones et al., 1998, 2001; Mann et al., 1998). At a higher temporal resolution, $1690-1700$ is considered to be the coldest decade for the 17th century in the northern hemisphere (Jones et al., 1998; Crowley and Lowery, 2000) including Iceland (Ogilvie and Jónsson, 2001), and this is reflected by the highest abundance of the $\mathrm{IP}_{25}$ biomarker in the MD99-2275 sediment core over the past 1000 years (Figs. 3 and 4).

$\mathrm{IP}_{25}$ is also abundant in sediments dated $1776,1638,1364,1331$ and 1309 corresponding to decades where large amounts of sea ice have been reported around Iceland (Ogilvie and Jónsson, 2001). In addition, these dates correspond to cold decades as shown by both the diatombased sea surface temperatures (Fig. 3; Jiang et al., 2005) and the mean northern hemisphere temperatures (Fig. 4; Crowley and Lowery, 2000). For the 19th century, Ogilvie and Jónsson described a highly variable climate with a succession of cold and mild decades. $\mathrm{IP}_{25}$ abundances are similarly variable during this period with the highest abundances of $\mathrm{IP}_{25}$ observed in the more recent sediments, in agreement with the historical data describing the latter part of the 19th century as the coldest.

The current $\mathrm{IP}_{25}$ data also provide additional sea ice information for periods where the historical sources are limited or unreliable. For example, very little data about Icelandic climate is available for periods corresponding to the earliest days of Iceland colonisation (ca. 870) to the end of the 13th century and from 1430 to 1560 (Ogilvie and Jónsson, 2001) and it is often assumed that the climate of Iceland was favourable during these periods. However, the frequent incidence of dramatic reductions in population due to documented famine and epidemics during these times, which may themselves be attributed in part to severe climatic conditions, could equally account for absences in climatic records (Ogilvie and Jónsson, 2001). The epoch immediately following the first colonisation period corresponds to the end of the MWP and therefore little or no sea ice might be predicted for this time. Consistent with this hypothesis, $\mathrm{IP}_{25}$ abundances are indeed low with mean values for 800-1300 lower than the subsequent 700 years (Fig. 3 ). This is also in agreement with diatom-based sea surface temperature reconstructions and northern hemisphere temperature profiles, both of which show warmer temperatures during this time (Figs. 3 and 4). Significantly, however, higher abundances of $\mathrm{IP}_{25}$ are observed for the few years when severe weather was reported including 1048 and 968 (Bergthórsson, 1969; Ogilvie and Jónsson, 2001; Fig. 3). $\mathrm{IP}_{25}$ abundances are also low between 1400 and 1460 and during the 16th century, consistent with reports of a mild climate (Ogilvie and Jónsson, 2001) and the diatom-based temperature record (Fig. 3). However, our data shows dramatic differences for the mid-late 15th century, where there are abrupt increases in the abundance of $\mathrm{IP}_{25}$ (particularly 1494, 1474 and 1467), reflecting enhanced sea ice occurrences due to more severe conditions during this period, with the centennial mean close to that of the preceding 14th century, for which reliable historical records suggest several severe decades (Ogilvie and Jónsson, 2001). Thus, despite a paucity of historical climate records for the 1430-1560 era, we provide compelling evidence for substantial changes in climate during this time including a 40-50-year period of extensive sea ice cover. Interestingly, these rapid and dramatic changes in the abundance of $\mathrm{IP}_{25}$ during the mid-late 15 th century are also consistent with substantial oscillations observed in the diatom-based temperature record (Fig. 3). Additional abrupt and coincident changes in both the $\mathrm{IP}_{25}$ abundances and sea surface temperatures are observed during the 14th, 17th and 18th centuries (e.g. 1364, 1638, 1688 and 1776) confirming that a number of substantial climate changes occurred in Iceland during the LIA.

As such, the high resolution and continuous dataset achieved in this study has enabled several abrupt changes to sea ice conditions to be determined for which there have been little or no precedent from previous decadal (or longer timescale) determinations (Fig. 3). Since debates continue as to what extent epochs such as the LIA and MWP can be classified in both temporal and spatial terms, our sea ice dataset illustrates that, for north Iceland (at least), substantial, abrupt and highly frequent changes to climate conditions are confirmed to have taken place within the well accepted centennial scale trends derived 
previously. Not only will such data enhance the quality of climate prediction models but, for locations where there is the additional impact on past human populations, a more accurate account of climate-induced control over human activity should become achievable.

\section{Conclusion}

This first application of a novel sea ice proxy has involved a comparison between the abundances of a sea ice derived biomarker found in an Icelandic sediment core with historical sea ice records, diatom-based sea surface temperatures and mean northern hemisphere temperatures. For the last millennium, we demonstrate a significant set of correlations between the abundance of the $\mathrm{IP}_{25}$ biomarker and at least one (and often two or all three) of these other climatic measures. As such, we have been able to make cross comparisons with other proxy methods and validate existing historical sea ice records. In addition, the cross correlation approach using $\mathrm{IP}_{25}$ abundances and other proxies has yielded new historical sea ice data for periods where records are scarce or absent and, in addition, has provided more convincing evidence for abrupt changes to sea ice and/or climate conditions, especially during the Little Ice Age. $\mathrm{IP}_{25}$ will likely provide an invaluable tool for future palaeoclimatic studies for regions where historical data are absent and periods before written records began.

\section{Acknowledgements}

This work was supported by the UK Natural Environment Research Council (NE/D013216/1; NE/E00752X/1). This is a contribution to the European Union 5th Framework project PACLIVA (Contract No. ECK2CT-2002-00143). This is LSCE contribution number 2435.

\section{References}

Belt, S.T., Massé, G., Poulin, M., LeBlanc, B., Michel, C., Rowland, S., 2007. A novel chemical fossil of palaeo sea ice: $\mathrm{IP}_{25}$. Org. Geochem. 38, 16-27.

Bergthórsson, P., 1969. An estimate of drift ice and temperature in Iceland in 1000 years. Jökull 19, 94-101.

Crowley, T.J., 2000. Causes of climate change over the past 1000 years. Science 289 270-277.

Crowley, T.J., Lowery, T.S., 2000. Northern hemisphere temperature reconstruction. Ambio 29, 51-54.
Eiriksson, J., Larsen, G., Knudsen, K.L., Heinemeier, J., Simonarson, L.A., 2004. Marine reservoir age variability and water mass distribution in the Iceland sea. Quat. Sci. Rev. 23, 2247-2268.

Eiriksson, J., Bartels-Jonsdottir, H.B., Cage, A.G., Gudmundsdottir, E.R., KlitgaardKistensen, D., Marret, F., Rodrigues, T. Abrantes, F. Austin, W.E.N., Jiang, H., Knudsen, K.L., Sejrup, H.P., 2006. Variability of the North Atlantic current during the last 2000 years based on shelf bottom water and sea surface temperatures along an open ocean/shallow marine transect in western Europe. The Holocene 16, 1017-1019.

Jiang, H., Eiriksson, J., Schultz, M., Knudsen, K.L., Seidenkrantz, M.S., 2005. Evidence for solar forcing of sea surface temperature on the North Icelandic Shelf during the late Holocene. Geology 33, 73-76.

Jones, P.D., Briffa, K.R., Barnett, T.P., Tett, S.F.B., 1998. High-resolution palaeoclimatic records for the last millennium: interpretation, integration and comparison with General Circulation Model control-run temperatures. The Holocene 8, 455-471.

Jones, P.D., Osborn, T.J., Briffa, K.R., 2001. The evolution of the climate over the last millennium. Science 292, 662-667.

Knudsen, K.L., Eiriksson, J., 2002. Application of tephrochronolgy to the timing and correlation of palaeocanographic events recorded in Holocene and late Glacial shelf sediments off North Iceland. Mar. Geol. 191, 165-188.

Knudsen, K.L., Eiriksson, J., Jansen, E., Jiang, H., Rytter, F., Gudmundsdottir, E.R., 2004. Palaeoceanographic changes off North Iceland through the last 1200 years: foraminifera, stable isotopes, diatoms and ice rafted debris. Quat. Sci. Rev. 23, 2231-2246.

Koch, L., 1945. The East Greenland ice, in: Komissionen for videnskabelige Undersøgelser i Grønland (Ed.), Meddelelser om Grønland, Copenhagen.

Larsen, G., Eiriksson, J., Knudsen, K.L., 2002. Correlation of late Holocene terrestrial and marine tephra markers, North Iceland: Implication for reservoir age changes. Polar Res. 21, 283-290.

Mann, M.E., Bradley, R.S., Hughes, M.K., 1998. Global-scale temperature patterns and climate forcing over the past six centuries. Nature 392, 779-787.

Ogilvie, A.E.J., 1992. Documentary evidence for changes in the climate of Iceland AD 1500 to 1800. In: Bradley, R.S., Jones, P.D. (Eds.), Climate since AD 1500, London and New York, pp. 92-117.

Ogilvie, A.E.J., Jónsson, T., 2001. "Little ice Age" research: a perspective from Iceland. Clim. Change 48, 9-52.

Rousse, S., Kissel, C., Laj, C., Eiriksson, J., Knudsen, K.L., 2006. Holocene centennial to millennial-scale climatic variability: evidence from high-resolution magnetic analyses of the last 10 cal kyr of North Iceland (core MD99-2275). Earth Planet. Sci. Lett. 242, 390-405.

Rowland, S.J., Robson, J.N., 1990. The widespread occurrence of highly branched acyclic $\mathrm{C}_{20}, \mathrm{C}_{25}$ and $\mathrm{C}_{30}$ hydrocarbons in recent sediments and biota - a review. Mar. Environ. Res. 30, 191-216.

Rowland, S.J., Belt, S.T., Wraige, E.J., Massé, G., Roussakis, C., Robert, J.-M., 2001. Effects of temperature on polyunsaturation in cytostatic lipids of Haslea ostrearia. Phytochemistry 56, 597-602.

Sicre, M.-A., Jacob, J., Ezat, U., Rousse, S., Kissel, K., Eiriksson, J., Knudsen, K.-L., Jansen, E., Turon, J.L., 2008. Decadal variability of sea surface temperatures off North Iceland over the last 200 yrs. Earth Planet. Sci. Lett. 268, 137-142.

Thomas, D.N., Dieckmann, G.S., 2003. Sea-Ice: An Introduction to its Physics, Chemistry, Biology and Geology. Blackwell, p. Oxford. 